IUSS

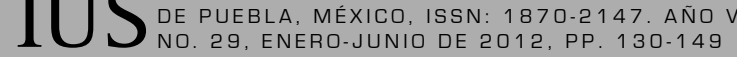

\title{
Autonomía de la voluntad y filiación: los desafíos del siglo $\mathrm{XXI}^{*}$ \\ Party autonomy and affiliation: challenges of the 21st century
}

\author{
Montserrat Pereña Vicente**
}

\section{RESUMEN}

La legislación española sobre técnicas de reproducción asistida ha supuesto una alteración importante en las normas tradicionales sobre determinación de la filiación, sobre todo si tenemos en cuenta que se permite recurrir a las mismas no sólo a las parejas heterosexuales con problemas reproductivos sino también a parejas homosexuales y a mujeres solas. Sin embargo, no se admite en España la gestación por sustitución. Esto ha provocado el aumento de los casos de "turismo reproductivo" en el que las personas que no pueden acceder a esta técnica en nuestro pais viajan a otro en el que si está permitida y posteriormente pretenden el reconocimiento de la filiación del niño asi nacido en el extranjero.

PALABRAS CLAVE: Filiación, gestación por sustitución, vientre de alquiler, reproducción asistida.

\begin{abstract}
Spanish legislation on assisted reproduction techniques has involved an important change in the traditional regulations related to the determination of affiliation, especially if we consider that we can resort to these not only in the case of heterosexual couples with reproductive problems but also same-sex couples and single women. However, surrogate mothers in Spain are prohibited. This has resulted in increased cases of "reproductive tourism" where people who cannot access this technique in our country, travel to another in which it is allowed, and later they aim at the recognition of the affiliation of a foreign-born child.
\end{abstract}

KEY WORDS: Affiliation, surrogate mothers (surrogacy), assisted reproduction.

\footnotetext{
* Recibido: 8 de febrero de 2012. Aceptado: 10 de marzo de 2012.

* Profesora titular de Derecho civil en la Universidad Rey Juan Carlos de Madrid, España. (montserrat.perena@urjc.es).
} 


\section{Sumario}

1. Madre biológica, madre genética y madre psicológica, afectiva, por consentimiento

2. Las incoherencias de la legislación española sobre filiación

A) Discordancias generales

B) Las incoherencias propias de la Ley de Técnicas de Reproducción Humana Asistida

3. La solución de la Dirección General de Registros y del Notariado

4. ¿Hacia una regulación de la gestación por sustitución?

A) Naturaleza de la gestación por sustitución

B) Supuestos en los que se permite

c) El consentimiento como determinante de la filiación

5. Conclusión

Tratar de determinar cuál es la esencia de la filiación nos conduce irremediablemente a poner en la balanza biología y voluntad. Ambos pueden y suelen ser componentes de la filiación, pero no podemos obviar la idea de que la voluntad es generadora, por sí sola, de filiación; es decir, que el consentimiento crea un vínculo de filiación idéntico a la filiación biológica desde el momento en que la ley reconoce a la adoptiva los mismos efectos.

Ahora bien, al tratar de aplicar esta conclusión a la filiación resultante de técnicas de reproducción asistida, especialmente en lo que se refiere a la gestación por sustitución, los planteamientos no son tan sencillos y las conclusiones a las que se llega no son pacíficas, ya que aparecen otros argumentos como la indisponibilidad del cuerpo humano o la dignidad de la persona, especialmente de la mujer gestante.

En una cuestión en la que tan fuertemente confluyen convicciones morales, religiosas, deontológicas, filosóficas, médicas y humanas, el derecho debe avanzar con cautela para adaptarse a la moral dominante, pero, a la vez, el derecho no puede vivir de espaldas a los avances de la ciencia y a lo que "de hecho" es una realidad social. La revolución que en las últimas décadas se ha producido por los avances médicos en las técnicas de reproducción asistida no puede, sin embargo, ocultar la realidad de que la gestación de sustitución es tan antigua como la humanidad. Como apunta el profesor HAUSER, ${ }^{1}$ sería naif creer que la gestación de sustitución de niños es una invención de nuestra época; basta con leer el Génesis para descubrir a lsmael, hijo de Sarah y Abraham, gestado por su sirviente Agar. No en vano, los artículos 959 y siguientes del Código Civil,

\footnotetext{
1 HAUSER, J. "La gestation pour autrui : aspects juridiques et éthiques", La liberté de la personne sur son corps, Dalloz,
} Paris, 2010, pp. 85-103, esp. p. 86. 
MONTSERRAT PEREÑA VICENTE

redactados en 1889, contienen disposiciones para evitar la suposición del parto. Precisamente el parto es el centro del debate, ya que es éste el que determina la filiación materna.

La legislación española en materia de reproducción asistida es de las más permisivas de Europa, si bien sigue manteniendo la prohibición de la gestación por sustitución (GXs) al reconocer como hecho determinante de la maternidad el parto, obviando cualquier otra consideración. Esta norma impide reconocer la filiación a favor de aquel o aquellos que tienen la voluntad o intención de ser padres del niño así gestado. Sin embargo, en los últimos meses, la aplicación del criterio del interés superior del menor ha permitido que se reconozcan algunos efectos, siempre que se cumplan determinadas condiciones que analizaremos posteriormente. Quizás esto sea un primer paso para legalizar en España el vientre de alquiler, pero nada hace pensar que esté próxima una reforma en ese sentido.

\section{Madre biológica, madre genética y madre psicológica, afectiva, por consentimiento}

El artículo 10 de la Ley 14/2006, de 26 de mayo, sobre Técnicas de Reproducción Humana Asistida (LTRHA) no deja lugar a dudas sobre los efectos de una convención de vientre de alquiler al imponer la nulidad de pleno derecho del contrato por el que se convenga la gestación, con o sin precio, a cargo de una mujer que renuncia a la filiación materna a favor del contratante o de un tercero, quedando determinada "la filiación de los hijos nacidos por gestación de sustitución por el parto”. Sin embargo, la realidad muestra que hay múltiples maneras de eludir esta prohibición, tanto dentro como fuera de España. La admisión de esta técnica en otros países ha dado lugar a lo que se viene conociendo como "turismo reproductivo", fenómeno por el cual parejas que, por diversos motivos, no pueden gestar su propio hijo, recurren a una "madre de alquiler" en uno de esos países en los que se admite la técnica. El impacto mediático que han tenido algunos casos de famosos homosexuales hace que, en ocasiones, perdamos de vista que son también parejas heterosexuales las que, por razones médicas o de otro tipo, pretenden recurrir a un vientre de alquiler. Así, los diferentes supuestos que podemos encontrar son:

1) Pareja heterosexual que, aportando su material genético, es decir, los óvulos de la mujer y el esperma del hombre, necesitan un vientre que geste el embrión fecundado in vitro. 
2) Persona sola, hombre o mujer, que, aportando o no su material genético, necesita la gestación de sustitución para el nacimiento del niño.

3) Pareja homosexual o heterosexual en la que sólo uno de ellos aporta su material reproductor, de manera que la procreación es parcialmente heterónoma, y la gestación se produce en el vientre de una mujer ajena a la pareja.

4) Pareja homosexual o heterosexual en la que ninguno de ellos aporta su material genético, de modo que los gametos con los que se realiza la fecundación son "ajenos” a la pareja.

En los tres últimos supuestos puede ocurrir que la mujer que aporta el vientre de alquiler aporte también su óvulo para la procreación, en cuyo caso se puede decir que la mujer que presta su vientre no sólo ha gestado sino que, además, ${ }^{2}$ ha "procreado para otro".

En todos los casos descritos, cualquiera que sea el origen del material genético empleado en la procreación, existe un elemento común a todos: la voluntad de una o dos personas de convertirse en padres, con independencia de la carga genética que tenga el niño y de quién lo vaya a gestar.

Es evidente que al legislador esa voluntad no le parece suficiente, ya que la prohibición absoluta que se consagra en nuestro ordenamiento jurídico hace que la filiación no pueda ser determinada legalmente respecto a los llamados ${ }^{3}$ "padres de intención", sino que viene determinada respecto de la madre que ha gestado y, por tanto, alumbrado al niño, incluso si ella no es la madre genética del mismo.

Es, quizá, el miedo paralizante al comercio con el cuerpo humano el que hace que, de forma excepcional, la voluntad no tenga relevancia para el derecho. $Y$ decimos de forma excepcional porque, como hemos apuntado, alguien puede convertirse en padre o madre sin que exista ninguna aportación genética ni gestación, por la simple concurrencia de su voluntad, como ocurre en la adopción, ${ }^{4}$ caso en el que, respecto a la madre genética y gestante, no se va a conservar vínculo alguno.

2 Pérez Vaquero, C. Diez claves para conocer los vientres de alquiler, Noticias Jurídicas, diciembre de 2010, p. 1: "En la subrogación tradicional (o parcial), la madre de alquiler es inseminada artificialmente para gestar un bebé con su propio óvulo (lo que conlleva, lógicamente, la contribución genética de la madre biológica al feto); mientras que en la subrogación gestacional (o plena), la madre de alquiler se limita a gestar el embarazo, puesto que ha sido inseminada artificialmente en un óvulo que no es suyo (puede que sea de quienes la contratan o que provenga de una donación anónima); en este caso, la mujer sólo alquilaría su útero".

${ }^{3}$ Terminología que deriva de la teoría de la intención elaborada por el Tribunal Supremo de California en el caso Johnson vs. Calvet en 1993.

${ }^{4}$ Si bien la adopción no se constituye solamente por la voluntad, sino que, siendo ésta esencial, se constituye por resolución judicial, de acuerdo con lo que dispone el artículo 176 del Código Civil. 
MONTSERRAT PEREÑA VICENTE

Esto hace que nos planteemos cuál es la esencia de la filiación, y más concretamente de la filiación materna. En los casos que podríamos denominar "ordinarios", la maternidad es el resultado de una voluntad, unos genes y una gestación, de modo que la mujer se convierte en madre por el efecto combinado de los tres.

Pero ¿qué ocurre si falta el componente genético? ¿Ya no existe posibilidad de ser jurídicamente madre? Nada más lejos de la realidad, ya que las técnicas de reproducción asistida permiten que a la mujer se le implante un embrión fecundado con un óvulo de una donante anónima, convirtiéndose en madre "biológica" del niño así procreado y respecto del cual, obviamente, no es la "madre genética".

Concluiremos, entonces, que la carga genética no es la esencia de la maternidad, ya que, en el caso, sólo la gestación y la voluntad concurren. ¿Cuál de los dos es el determinante de la filiación? Desde luego, en el caso descrito, ambos, pero ¿cuál es el esencial?

Dar respuesta a la cuestión no es tarea fácil. Quizá el único camino para encontrar una respuesta sea buscar cuál de los tres elementos descritos no puede faltar para que una mujer se convierta en madre. $Y$ eso sí es muy sencillo. Una mujer puede haber concebido un hijo aportando su óvulo, gestarlo y parirlo, pero si no tiene voluntad de ser madre, jurídicamente no lo será; su renuncia al niño para que éste sea adoptado hace que jurídicamente no se vaya a crear vínculo filial con ella. En cambio, una mujer puede no aportar ni su óvulo ni su útero para la gestación, pero si tiene voluntad, si consiente en ser su madre, se convertirá, por efecto de la adopción, en madre.

Concluyamos, sin ambages, que el único elemento esencial, el que no puede faltar para que se determine la maternidad, no para ordenamientos jurídicos extranjeros ni para los sociólogos, psicólogos o filósofos, sino para el ordenamiento jurídico español, es la voluntad. La misma voluntad que es esencial para que el marido o la pareja de una mujer que se somete a una inseminación artificial con donación anónima de esperma se convierta en padre biológico del niño que nace, creando en este caso el vínculo de filiación únicamente sobre la voluntad del hombre que nada biológico ni genético aporta.

134 La pregunta que nos hacemos entonces es por qué nuestro ordenamiento reconoce efectos jurídicos al hecho de alumbrar un niño si la mujer que gesta y da a luz no tiene voluntad de ser madre y, en muchos casos, el niño no tiene su carga genética sino, precisamente, la de la madre que lo quiere ser por voluntad. ¿Cuál es la razón para que la Ley imponga una maternidad contra la voluntad? lsraël NisAND, ${ }^{5}$ catedrático de Ginecología de la cHu de Estrasburgo, a la pregunta

${ }_{5}^{5}$ NISAND, I. "La gestation pour autrui : pour le cas par cas", La liberté de la personne sur son corps, cit., pp. 77-83. 
de quién es la verdadera madre, si la que gesta el niño o la que aporta el material genético, responde que ni una ni otra, ya que la única que es verdadera madre es la que "adopta psíquicamente" al niño. Esto es lo único que convierte a la mujer en madre, ya que, aunque exista gestación y aportación genética, si no existe esta "adopción psíquica" o sentimental, no hay maternidad.

A pesar de esta evidencia, la gestación por sustitución genera el rechazo de muchos juristas, ${ }^{6}$ aunque no faltan autores que abogan por su regulación. ${ }^{7}$ Los argumentos que se esgrimen para rechazarla ponen de manifiesto que tal práctica supone un atentado contra la prohibición de disponer y comerciar con el propio cuerpo, y nos parece, desde luego, un argumento importante y que, en toda reflexión seria en la materia, no puede obviarse. Sin embargo, ¿no es igualmente disposición del propio cuerpo la donación de óvulos y esperma que hacen los donantes anónimos que permiten que una mujer se convierta en madre de un hijo que no tiene nada genéticamente de ella ni de su pareja?

El argumento de hacer entrar en el comercio el cuerpo humano nos debería conducir a rechazar también la donación de óvulos y esperma y, en general, cualquier donación de órganos, y sin embargo la solución de nuestro ordenamiento jurídico no es ésta, sino, muy al contrario, permitirlas e incluso alentarlas, estableciendo unos procedimientos y cautelas que impiden que se comercie con ellos, pero permitiendo la donación, es decir, la disposición sobre el cuerpo con intención liberal. Es decir, lo que genera rechazo a la ley española no es la posibilidad de disponer del propio cuerpo, sino la idea de hacerlo a título oneroso, aunque -como subraya QuiNonEs EscÁmEZ-8 "nadie que haya dado a luz dirá que llevar un hijo en el vientre es equivalente a llevar un hígado o un riñón o a donar los gametos. La gestación genera, de un modo u otro, vínculos entre la madre y el niño". Las implicaciones éticas y morales de la gestación por sustitución impiden a muchos incluso plantear la posibilidad de su admisibilidad en los casos en los que no hay contraprestación, de acuerdo con el sentir mayoritario de juristas y no juristas. ${ }^{9} \mathrm{Y}$ es que la cuestión de la contraprestación no es el único

\footnotetext{
${ }^{6}$ Muñoz de Dios SÁez, L. F. "¿Se ha legalizado o no el alquiler de vientres?", en El Notario del Siglo XXI, No. 34, diciembre de 2010: "Para justificar el disfavor con que vemos el contrato de alquiler de vientres basta con analizar las motivaciones que llevan a las mujeres que prestan sus vientres para gestaciones para terceros. La mayoría de las veces económica, buscan dinero, lo que hace adecuada la denominación usual de 'alquiler"'.

7 Lasarte Álvarez, C. "La reproducción asistida y la prohibición legal de maternidad subrogada admitida de hecho por via reglamentaria", en La Ley, №. 7777, 17 de enero de 2012, p. 7: "[...] probablemente sea más razonable admitir la maternidad subrogada y que quienes deseen obtener descendencia, superando los problemas de infertilidad, puedan recurrir a dicha técnica, al menos cuando puedan ofrecer a los futuros nacidos un entorno familiar que resulte adecuado y se considere tal por el legislador patrio".

${ }^{8}$ Quiñones EscÁmez, A. Doble filiación paterna de gemelos nacidos en el extranjero mediante maternidad subrogada, InDret, julio de 2009, p. 18 (www.indret.com).

${ }^{9}$ Lacruz Berdejo, J. L. Elementos de derecho civil IN, puesto al día por J. Rams Albesa, Dykinson, Madrid, 2008, p. 363:
} 
argumento que existe para rechazar frontalmente la práctica de los vientres de alquiler que toca muy de cerca cuestiones relativas a la dignidad de la persona, y especialmente de la mujer que realiza la gestación por cuenta o encargo de otro, ya que, como subraya SÁNCHEZ ARISTI, ${ }^{10}$ esta práctica genera mayor rechazo que las técnicas tradicionales de reproducción asistida porque en la gestación por sustitución "la mujer gestante no hace entrega de una parte separable de su cuerpo, sino que pone a disposición de otras personas algo tan intransferible y ligado a su propia integridad física como es su útero".

El presente estudio no pretende hacer consideraciones éticas o morales a favor o en contra de la gestación por sustitución. Otros autores ${ }^{11}$ se han ocupado ya de la cuestión y a ellos nos remitimos, ${ }^{12}$ aunque no pretendemos disociar los aspectos éticos del razonamiento jurídico, ni se puede olvidar en éste que es la esencia misma de la vida, el poder de "crear", lo que se juega en este procedimiento que consiste, si llamamos a las cosas por su nombre, en "hacer niños por encargo". Gráficamente, el profesor HAUSER ${ }^{13}$ lo denomina la "externalización de la fábrica de niños". Nuestra intención es tratar de poner de manifiesto las contradicciones existentes en la legislación española y las que el Ministerio de Justicia ha generado al tratar de "solucionar" algunos de los problemas que la realización de esta práctica en el extranjero provoca. Solución que se ha hecho a través de normas de rango inferior que, invocando el interés superior del menor, convierten en válido lo que la ley declara nulo.

"Lo conflictivo de esta materia en si se ha complicado más en la vida real desde el momento en que han surgido intermediarios con ánimo de lucro, y contratos onerosos con grandes cantidades para retribuir la colaboración de otra mujer con la gestación necesitada. No hace falta mucha imaginación ni sensibilidad para comprender el rechazo mayoritario, casi unánime en la doctrina (sobre todo europea, y en la española) y en las leyes o trabajos legislativos e informes de Comisiones ad hoc, tanto de esa realidad como de la mediación y contratos aludidos, con algunas excepciones para los casos en que aquella colaboración sea altruista y sin remuneración alguna a título de contraprestación. Mayor apertura puede apreciarse en la doctrina y tribunales anglosajones (sobre todo en USA), y en algún ordenamiento americano.

Creo innecesario detenerme a criticar, desde cualquier punto de vista (ético, social, jurídico), ese mercado degradante que pretende disfrazar bajo cierta juridicidad egoísmos y actuaciones lindantes con lo penal y conductas atentatorias a la dignidad de la mujer-madre y, en general, de la persona humana".

10 Sánchez ArISti, R. "La gestación por sustitución: dilemas éticos y juridicos", en Humanitas Humanidades Médicas, No. 49, abril de 2010, pp. 13-38, esp. p. 25

1 En contra, Muñoz de Dios, L. F. "El Registro Civil admite el alquiler de vientres", en El Notario del Siglo xxI, No. 27, y en "¿Se ha legalizado...?", op. cit; a favor, AtıEnZA, M. "De nuevo sobre las madres de alquiler", en El Notario del Siglo XXı, No. 27, y VelA SÁnChez, A. J. "La gestación por sustitución o maternidad subrogada: el derecho a recurrir a las madres de alquiler", en La Ley, No. 7608, 11 de abril de 2011, y en "De nuevo sobre el régimen del convenio de gestación por sustitución o de maternidad subrogada en España", en La Ley, No. 7815, 9 de marzo de 2012.

12 Bercovitz Rodriguez-Cano, R. Hijos made in California, Aranzadi Civil-Mercantil No. 3/2009, p. 2: "No es cierto que la inscripción en nuestro Registro Civil de hijos naturales por gestación de sustitución sea contraria a nuestro orden público internacional. Es manifiestamente contrario a la dignidad que nuestra Constitución y nuestra sociedad reconoce a la mujer. Es contraria a los principios básicos de nuestro derecho".

13 HAUSER, J., "La gestation...", op. cit., p. 86: "L'externalisation de la fabrique des enfants a commencé par des expressions insusceptibles d'initiales". 


\section{Las incoherencias de la legislación española sobre filiación}

En materia de procreación asistida, España ha sido pionera, tanto desde el punto de vista médico como desde el punto de vista jurídico, ya desde la Ley de 1994. La combinación de esta precocidad con el reconocimiento que en los últimos años se ha hecho de los derechos de las personas homosexuales permite que todas las combinaciones y razones posibles sean válidas para la ley y, por tanto, produzcan efectos jurídicos en lo que se refiere a la determinación de la filiación. Sin embargo, la improvisación y la falta de rigor técnico, de la que tan a menudo hace gala el legislador, genera que, en algunos casos, existan incoherencias o contradicciones en la ley que provocan diferencias de trato no justificadas.

\section{A) Discordancias generales}

Algunas de las imprecisiones que se contienen en la regulación de la filiación proceden del hecho de que el concepto de la filiación por naturaleza, a la que se refieren los artículos 108 y siguientes del Código Civil, se basa en sus orígenes en una realidad biológica, real o presunta, pero en todo caso inverificable en otras épocas, mientras que ahora también se basa en ficciones a las que la ley otorga efectos jurídicos. Estas ficciones se refieren tanto a la filiación paterna como a la materna.

Por un lado, la correspondencia entre realidad biológica y filiación natural desaparece en muchos casos de reproducción asistida en los que se va a determinar la filiación natural respecto de progenitores que no han hecho aportación de material reproductor, sino que, como en la adopción, simplemente han consentido: se produce este efecto cuando el marido o la compañera de la mujer que es inseminada artificialmente con semen de donante anónimo, consiente que se determine la filiación natural respecto de él o ella, en cuyo caso, además, el artículo 8 determina que no podrá impugnar la filiación; y se produce también este efecto por imperativo del artículo 8 de la LTRHA, que en su número 3 permite que la mujer casada con otra mujer pueda manifestar ante el encargado del Registro Civil "que consiente en que cuando nazca el hijo de su cónyuge se determine a su favor la filiación respecto al nacido". En este caso, apunta SÁnchez ARISTI, ${ }^{14}$ la filiación que opera por el mero consentimiento produce "la rareza de que el hijo nacido en esas circunstancias tendría dos madres por naturaleza".

\footnotetext{
$\overline{14}$ Sánchez Aristi, R. "La gestación...", op. cit., p. 33.
} 
MONTSERRAT PEREÑA VICENTE

Por otra parte, la filiación por naturaleza en relación con la madre se basa en el parto, que, hasta hace relativamente poco tiempo, presuponía siempre la aportación del material genético de esa misma mujer. Es decir, las normas sobre filiación basadas en postulados antiguos no podían tener en cuenta la disociación que hoy día, por la aparición de la técnica de la implantación de embriones fecundados in vitro, es posible: puede haber una mujer que geste y otra que haga la aportación genética, y esa realidad es totalmente ajena a la regulación de la filiación materna en el Código Civil. Incluso en la LTRHA tampoco se hace referencia a esta disociación, si bien el artículo 8, que determina la imposibilidad de impugnar la filiación del hijo nacido con consentimiento de donantes anónimos, sean de óvulos, de esperma o de ambos, respecto a la filiación materna, no "impone" esta filiación basándose en el hecho del parto, sino basándose en el "consentimiento formal, previo y expreso" de la mujer, es decir, en la voluntad y no en la gestación.

Pero además, en las dos últimas décadas los cambios normativos y sociológicos producidos en España han hecho que la filosofía que inspiraba el reconocimiento de efectos jurídicos a las técnicas de reproducción asistida hayan cambiado por completo. Se ha pasado del aspecto médico, al considerarlas como un modo de solucionar los problemas de infertilidad de una pareja, al terreno de los derechos: ${ }^{15}$ el derecho a la vida familiar, el derecho a ser madre o padre en solitario y con independencia de la orientación sexual... filosofía que ha sido potenciada por las decisiones del Tribunal Europeo de Derechos del Hombre, que, en sentencias como la del 3 de noviembre de 2011, consagra "el derecho de las parejas a concebir un hijo recurriendo a las técnicas de reproducción asistida", derecho que, como indica Adeline GouTTEnoire, ${ }^{16}$ se funda o basa en el derecho a la vida privada y familiar.

Esta dinámica, peligrosa, ha permitido que se abra paso el "derecho de procrear recurriendo a las técnicas de reproducción asistida” tanto a parejas casadas como no casadas, homosexuales y heterosexuales, y a las mujeres solas. $\mathrm{Y}$ es aquí donde empiezan los problemas, ya que al ser la mujer actora principal del proceso de creación, es en ella en la que se centra la ley. En una legislación en la que se han puesto patas arriba instituciones como el matrimonio y la filiación para garantizar la igualdad del hombre y la mujer, con independencia de

\footnotetext{
${ }^{15}$ Así lo ha puesto de manifiesto HAUSER, J. "L'intérêt supérieur et la filiation de l'enfant issu d'une procréation médicalement assistée", en La maîtrise de la vie, Eres, pp. 187-198, esp. p. 190: "D'un côté, l'analyse exagérée de l'ensemble du droit civil des personnes et de la famille, voire de l'ensemble du droit, en termes de "droits à... " étrange revanche des droits subjectifs que l'on vouait aux gémonies au début du siècle précédent, comme étant des vecteurs d'individualisme outrancier, de délitement du lien social et surtout d'oppression des forts sur les faibles ".

${ }^{16}$ Gouttenoire, A. "La famille dans la jurisprudence de la Cour européenne des droits de l'homme", Droit de la Famille, marzo de 2012, pp. 11-15.
} 
su orientación sexual, y en la que "el derecho a..." se ha convertido en el centro del sistema, resulta que el hombre, según la lógica propia de toda esta filosofía legislativa, es de peor condición que la mujer, al no tener cabida en la ley su "derecho a la paternidad en solitario". Excede el objetivo del presente trabajo valorar la oportunidad de consagrar ese "derecho a ser madre en solitario" que la ley reconoce al permitir que la mujer sola recurra a las técnicas de reproducción asistida. No en vano el artículo 6 de la Ley de 2006, bajo el enunciado "usuarios de las técnicas", consagra a "toda mujer mayor de 18 años y con plena capacidad de obrar" como receptora o usuaria de las técnicas reguladas en la Ley. Tampoco vamos a detenernos en la cuestión de la conveniencia o no de consagrar el derecho de las parejas homosexuales a ser padres. Lo único que queremos poner de manifiesto es que toda la terminología del Código Civil relativa a la determinación de la filiación no se ha adaptado a estos "nuevos derechos", y de ahí surge parte de los desajustes.

Desajustes e incoherencias que se acentúan porque, desde hace años, nuestro legislador se empeña en incorporar altas dosis de relativismo al derecho de familia; relativismo que se basa en considerar que la igualdad es un rodillo que nos pasa por encima y borra las diferencias, convirtiéndonos a todos en seres asexuados. Pero la igualdad no exige que la ley nos haga a todos iguales. Lo que exige es que nos garantice los mismos derechos aunque seamos diferentes. Se podrá defender, de acuerdo con la teoría de los derechos, el derecho a ser padre o madre en solitario o en compañía de otro padre o madre. Pero lo que no se puede defender es que un padre y una madre son lo mismo, como no es lo mismo ser hombre que mujer. Las leyes no pueden borrar el significado que las palabras tienen, lo que representan, porque esto es previo a la ley.

Ejemplos más coherentes, aunque no forzosamente mejores, encontramos en otras legislaciones cercanas como la francesa. En el país vecino, las técnicas de reproducción asistida siguen siendo fieles a sus orígenes: son un mecanismo admitido, regulado y reconocido, cuyo único objetivo es ayudar a las parejas con problemas de infertilidad a tener descendencia. Al no estar permitidos los matrimonios ni la adopción por homosexuales en Francia, sólo se permite a las parejas heterosexuales y no a la mujer sola, ya que el planteamiento de la ley no se basa en el reconocimiento de derechos, como el "derecho a ser madre en solitario", sino que se hacen prevalecer las cuestiones médicas y, en caso de llevarse al terreno de los derechos, se hace prevalecer ${ }^{17}$ el "derecho del hijo a tener un padre y una madre”. Tratándose de parejas heterosexuales, únicas posibles destinatarias

\footnotetext{
${ }^{17}$ Hauser, J. "L'intérêt supérieur...", op. cit., p. 193: " [...] On ne sait pas trop où est l'intérêt supérieur de l'enfant de
} naître orphelin?". 
MONTSERRAT PEREÑA VICENTE

de estas técnicas en Francia, ni siquiera se permite la procreación totalmente heterónoma, es decir, en la que existe donación tanto de óvulo como de semen, y, evidentemente, se prohíbe también la gestación de sustitución. En palabras de NISAND, ${ }^{18}$ la legislación francesa tiene la virtud de la claridad: lo prohíbe todo. Ahora bien, esta coherencia legal no impide la aparición de numerosos casos problemáticos en los que el Estado ha de decidir sobre la filiación de un niño nacido en el extranjero, en el que están implicados uno o dos franceses, utilizando una técnica de reproducción asistida no permitida en Francia. Las incoherencias no se muestran en la ley sino en las soluciones judiciales, que pueden ser diferentes en casos similares. La Ley de Bioética aprobada en Francia en 2011 no ha modificado en lo esencial la materia, a pesar de que en el proyecto de esta Ley se incorporaron grandes cambios que han desaparecido del texto definitivo.

B) Las incoherencias propias de la Ley de Técnicas de Reproducción Humana Asistida

Volviendo al derecho español, ante la nulidad del contrato por el que se conviene la gestación por sustitución, los problemas encontrados se centran, como en Francia, en el reconocimiento de la filiación del niño nacido utilizando esta técnica en el extranjero. Como ocurriera en el Génesis, no podemos ignorar que, sin necesidad de viajar, dentro de nuestras fronteras el recurso a la madre de alquiler por parte de parejas homosexuales y heterosexuales se hace en la clandestinidad, y en estos casos, con mucha frecuencia, existe compensación económica. Una búsqueda rápida en Google basta para darse cuenta de que esto no es ciencia ficción. Estos casos se desenvuelven y practican en la sombra y las soluciones van desde la suplantación de la personalidad en el momento del parto, en el que la gestante declara el nombre de la madre de intención y no el suyo, hasta acuerdos entre el padre biológico homosexual, que engendra un hijo de forma natural, es decir sin recurrir a técnicas de reproducción asistida, con una mujer que, a cambio de dinero o no, consiente que el hijo sea criado por el padre, realizando, de hecho, una renuncia a su maternidad.

Estos casos difícilmente trascienden. Los que conocemos son aquellos en los que el o los "progenitores de intención" han recurrido a una gestante en un país en el que la técnica está permitida y pretenden el reconocimiento en España de la filiación del niño así nacido a su favor. Los casos más mediatizados suelen producirse con las surrogate mothers californianas, ya que en este estado americano

${ }_{18}$ Nisand, l. "La gestation...", op. cit., p. 78. 
se reconoce validez al procedimiento, tanto si es oneroso como si es gratuito, si bien dicho procedimiento está permitido en muchos otros países como Bélgica, Reino Unido, Grecia, Holanda, Brasil, India, Rumania, Rusia...

Es precisamente una gestación por sustitución realizada por una pareja de hombres homosexuales españoles en California la que ha dado origen a las ya famosas sentencias del Juzgado de Primera Instancia No. 15 de Valencia, del 15 de septiembre de 2010, y de la Audiencia Provincial de Valencia, del 23 de noviembre de 2011, así como a la Resolución de la DGRN del 18 de febrero de 2009 $\mathrm{y}$, seguramente, la que ha impulsado la Instrucción de la DGRN del 5 de octubre de 2010, que ha conseguido algo inaudito: poner de acuerdo en las críticas que se le hacen a los partidarios y detractores de la gestación por sustitución. ${ }^{19} \mathrm{~A}$ todo ello nos referiremos posteriormente. Por el momento vamos a analizar las incoherencias de la Ley de Técnicas de Reproducción Humana Asistida.

1) La primera contradicción o incoherencia resulta de realizar una interpretación sistemática del artículo 10 de la LTRHA, que en su No. 2 determina que "la filiación de los hijos nacidos por gestación de sustitución será determinada por el parto", en relación con la legislación del Registro Civil, ${ }^{20}$ que permite a la mujer que alumbra el niño, que éste no sea declarado como hijo suyo, es decir, que no permite determinar la filiación materna contra la voluntad de la mujer gestante. Sin embargo, este No. 2 del artículo 10 parece no tener en cuenta que, precisamente, por definición, cuando existe el convenio de gestación subrogada, la mujer consiente en que no se determine a su favor la filiación materna del niño que gesta. Pero además, como pone de manifiesto QuiÑones Escámez, ${ }^{21}$ este precepto parece desconocer la realidad de que en el certificado registral estadounidense no consta el nombre ni la identidad de la gestante, que, de acuerdo con el derecho de California, no es tenida por madre.

2) La segunda incoherencia la encontramos también en la redacción del propio artículo 10 de la LTRHA, que, por una parte, declara "nulo de pleno derecho el contrato por el que se convenga la gestación, con o sin precio, a cargo de una mujer que renuncia a la filiación materna a favor del contratante o de un tercero", y por otra, en su No. 3 deja a salvo "la posible acción de reclamación de la paternidad respecto del padre biológico, con-

\footnotetext{
${ }^{19}$ Vela SÁnchez, A. J. "De nuevo...", op. cit., p. 1: "A pesar de su loable voluntad, que se le presume, la instrucción comentada no tiene cabida posible en nuestro ordenamiento jurídico".

${ }^{20}$ Artículo 167, párrafo 2, del Reglamento del Registro Civil: "El parte o declaración de los profesionales y personal de establecimientos sanitarios que tengan obligación de guardar secreto no se referirá a la madre contra su voluntad".

${ }^{21}$ QuiNonenes Escámez, A. Doble filiación..., cit., p. 6.
} 
MONTSERRAT PEREÑA VICENTE

forme a las reglas generales". Si un contrato es nulo, eso significa que no produce efectos, así que en el mismo artículo se consagra una nulidad que no es tal porque sí produce efectos a favor de la filiación paterna.

De acuerdo con este No. 3 del artículo 10, si el vientre de alquiler ha sido concertado por una pareja heterosexual, respecto de él podrá ser determinada la paternidad mediante el reconocimiento del hijo, que es la forma ordinaria de establecer la filiación paterna no matrimonial, si él ha aportado su semen, ya que el artículo se refiere al padre "biológico", y ello con independencia de que lo haya hecho utilizando una técnica de reproducción asistida o de "forma natural", y tanto si lo ha hecho en España como en el extranjero, ya que donde la ley no distingue no se puede distinguir. Pero ahí no terminan las incongruencias. Como hemos visto, en el derecho español la paternidad biológica se determina no sólo en aquellos supuestos en los que el varón aporta el semen, sino que también resulta de una técnica de reproducción asistida en la que el marido o compañero de la mujer que se somete a la misma ha consentido que la inseminación se realice con el semen procedente de un donante anónimo, por lo que nada impediría que el hombre pudiera simplemente reconocer la paternidad del niño, aunque éste no lleve su carga genética. Además, si son dos hombres los que han realizado la convención, dado que la ley española permite reconocer una doble paternidad respecto de ambos, ¿los dos pueden reconocer la paternidad biológica conforme a este No. 3?

3) La tercera incoherencia resulta, también, de esta salvedad que hace el No. 3 del artículo 10 a favor de la filiación paterna, que genera una diferencia de trato en relación con la mujer. Un hombre sí podría ser reconocido como padre biológico de un niño concebido mediante una convención de este tipo, pero una mujer no podría, incluso aunque haya aportado su óvulo para la procreación, es decir, aunque concurra en ella la voluntad y la aportación genética. Realmente complicado.

\section{3. La solución de la Dirección General de Registros y del Notariado}

"Vaya usted a otro país a celebrar un contrato declarado nulo por el derecho español y no se preocupe por nada que, cuando regrese, el contrato va a producir todos sus efectos". Así podríamos resumir el mensaje que lanza el Ministerio de Justicia con la Instrucción del 5 de octubre de 2010. Como ya hemos señalado, el efecto fundamental de la nulidad de un contrato es, precisamente, la ausencia 
total de efectos. Si la Dirección General reconoce esos efectos cuando el contrato se ha celebrado en el extranjero, es como si la ley ahora estableciese: "será nulo de pleno derecho el contrato celebrado en España por el que se convenga la gestación por sustitución; sin embargo, será válido el celebrado fuera de España y producirá plenos efectos en cuanto a la determinación de la filiación con arreglo a la ley española”. Esta caricaturización de la situación es, lamentablemente, la realidad. Éste es el efecto real de la Instrucción de la Dirección General, que parece haber olvidado que una instrucción no puede cambiar una ley, ni siquiera invocando el "interés superior del menor". Un juez sí puede invocar ese interés en la aplicación de una norma, pero un órgano de la administración no puede invocarlo para corregir, no en el caso concreto, sino para todos los casos que se produzcan en el futuro, los efectos de una ley.

Si la Ley de 2006 declara nulo el contrato de gestación de sustitución, privándole de efectos, alguna razón habrá. Y si ya no existe razón para que siga siendo nulo, se tendrá que permitir, pero modificando la ley con otra ley. Esto es de primero de licenciatura, ahora grado, por lo que no vamos a dedicarle más tiempo.

La cuestión resuelta por la ya famosa Resolución de la DGRN y las sentencias de Valencia es, fundamentalmente, una cuestión de derecho internacional privado en la que convergen y se entrelazan cuestiones relativas al reconocimiento en España de sentencias extranjeras, la inscripción en el Registro Civil español de las certificaciones de registros extranjeros, y la duda sobre cuál debe ser el alcance del control de legalidad sobre tales documentos realizado en España, o si la prohibición de la gestación por sustitución contemplada en el artículo 10 se considera o no como integrante del orden público internacional español e, incluso, si se trata de una ley de policía. A razonar y argumentar todas estas cuestiones se han dedicado numerosos trabajos doctrinales. Especialmente completo es el de QuiÑones EsCÁmEZ, ${ }^{22}$ por lo que no vamos a detenernos en repetir razonamientos que ya se han puesto de manifiesto. En cualquier caso, tanto la resolución como las sentencias se referian a un caso concreto, por lo que carecían de valor normativo general. No es el caso de la Instrucción de la DGRN, que, de acuerdo con su Exposición de Motivos, elabora unas directrices a las que "deberá ajustarse la práctica registral en esta materia en beneficio de su conveniente uniformidad y de la deseada seguridad jurídica".

En principio, parece que la Instrucción no pretende, no es su competencia, regular la licitud o ilicitud de una convención de gestación por sustitución, sino simplemente facilitar "la continuidad transfronteriza de una relación de filiación declarada por Tribunal extranjero"; sin embargo, lo hace. A través de la exigencia

\footnotetext{
22 Idem.
} 
MONTSERRAT PEREÑA VICENTE

de proceder a la inscripción, no mediante una certificación registral sino mediante resolución judicial que haya obtenido el exequátur, o bien mediante el control incidental que debe hacer el encargado del Registro Civil español, la DGRN impone sus propios criterios para determinar qué convenciones de gestación por sustitución producirán efectos en España y cuáles no. Con ello, sin decirlo, deja claro:

1) Que la prohibición del artículo 10 no forma parte del orden público internacional español ni es una ley de policía.

2) Que el recurso a la gestación por sustitución en un país extranjero no constituye fraude de ley.

3) Que no es posible la inscripción de la filiación cuando esta técnica haya sido utilizada en España, y es que, como muy acertadamente ha puesto de manifiesto Vela SÁNCHEZ, ${ }^{23}$ la Instrucción genera discriminación económica, ya que sólo permite el reconocimiento de la filiación a aquellos españoles que hayan tenido medios para recurrir a esta técnica en el extranjero. Es evidente que discriminación económica existe por muy diferentes motivos en todos los ámbitos; el problema, añadimos nosotros a la reflexión de VELA, es que esta Instrucción la institucionaliza.

\section{4. ¿Hacia una regulación de la gestación por sustitución?}

La Instrucción ha supuesto la consagración normativa de una gran hipocresía que, además, no soluciona todos los problemas planteados. ¿Qué va a responder la DGRN a una pareja que, aportando su material genético, haya recurrido clandestinamente a una gestación de sustitución en España? ¿Quizá que tendrían que haberse ido a Estados Unidos? ¿No podrá reconocer la filiación porque en este caso no existirá el "interés superior del menor"? ¿Ese interés superior del menor sólo existe si el menor ha nacido en el extranjero? La Dirección General ha abierto la puerta de atrás, no para solucionar un problema, sino para crear muchos otros.

Sólo cabe regular la materia por ley, y ésta deberá optar por mantener la prohibición, con todas las consecuencias que ello conlleve, o bien admitir y regular la gestación por sustitución.

A pesar de todas las objeciones que se puedan hacer a esta práctica, una realidad se abre paso, y es que -como subraya SÁnCHEZ ARISTI- ${ }^{24}$ la prohibición

${ }^{23}$ Vela SÁnchez, A. J. "La gestación por sustitución...", op. cit.

24 Sánchez Aristi, R. "La gestación...", op. cit., p. 37. 
legal no ha erradicado la práctica sino que la ha conducido a la clandestinidad. Es evidente que no es argumento suficiente para provocar el cambio legislativo la constatación de la falta de eficacia de la prohibición, debida en parte a su legalización fuera de nuestras fronteras; sería tan absurdo como exigir que se legalicen en España todas las prácticas aquí prohibidas que sean legales en otros países. Pero también nos parece evidente que ha de darse una solución legal que difícilmente va a pasar por una marcha atrás en lo que, al día de hoy, por vía de ley o de instrucción, ya se admite, por lo que, antes o después, se impondrá la solución permisiva que, en realidad, es la que la DGRN ha consolidado por la vía de los hechos consumados, aunque sólo a favor de aquellos españoles que tengan medios económicos suficientes para poder pagar todos los gastos que genera recurrir a esta práctica en el extranjero.

Ahora bien, de imponerse un cambio en la ley, lo que se debe exigir al legislador es que en un tema tan sensible no se imponga una reforma precipitada y de mínimos en la que simplemente se suprima el artículo 10 o éste pase de declarar nulo el contrato a establecer que será válido sin más. Autores como VELA SÁNCHEZ reclaman una "legislación razonable" en la materia. El problema reside en determinar qué entendemos por razonable. Eliminada la prohibición, los problemas no hacen más que empezar y el legislador debe tratar de anticiparse a ellos estableciendo un marco legislativo adecuado. La elaboración de esta normativa conllevará la elección de un modelo, más o menos restrictivo, en el que las opciones son variadas, por lo que una reflexión se impone para configurar una técnica en la que existe un amplio abanico de posibilidades entre las que el legislador debe elegir.

\section{A) Naturaleza de la gestación por sustitución}

Sobre lo primero que se debe reflexionar es sobre si es una técnica de reproducción asistida o si, por el contrario, su naturaleza se aproxima más a la adopción, porque de ello va a depender el régimen jurídico que se establezca.

Pocos autores se han planteado la cuestión. SÁnCHEZ ARIST1 ${ }^{25}$ lo hace y llega a la conclusión de que quizá lo más aconsejable sea aproximarla a la adopción, sometiéndola a un régimen jurídico semejante a ésta en los casos en los que no existe aportación de gametos por parte de los padres de intención, mientras que cuando sí exista esa aportación estaría más próxima de una técnica de repro-

\footnotetext{
25 Ibidem, p. 28.
} 
MONTSERRAT PEREÑA VICENTE

ducción asistida, si bien parece aproximarla en todo caso a la adopción, ya que la gestación por sustitución implica "una suerte de desamparo premeditado de un menor, desde el momento en que la mujer portadora adquiere el compromiso de entregar al niño con antelación, no ya al momento de nacer este niño, sino al momento de concebirlo".

Compartimos la conclusión de que su naturaleza se aproxima más a la adopción, pero no porque se produzca este desamparo, porque precisamente en este caso, por definición, no existirá desamparo, ya que la presencia de los padres de intención, que en ocasiones lo único que aportan es su voluntad, expresión de su deseo de tener ese hijo, impide que exista desamparo a pesar de la renuncia de la mujer gestante.

Sin embargo, la complejidad en la ejecución de la gxs en la que la "aportación” realizada por la mujer gestante se va a desarrollar durante nueve meses y la posible ausencia de todo vínculo biológico o genético de los padres de intención con el niño, que lo serán sólo por la existencia de su voluntad, aconsejan aproximar su régimen jurídico a la adopción, con la finalidad de que exista intervención de una autoridad judicial o administrativa, si bien esto no prejuzga la naturaleza de la filiación resultante ni puede conllevar la aplicación en bloque de la normativa sobre adopción, ya que las peculiaridades propias de la GXs impiden su asimilación total con ésta. Sin embargo, asimilarla, como hace Vela SÁnchez, ${ }^{26}$ con las técnicas de reproducción asistida no creemos que sea lo más adecuado, salvo que se exija para su realización en todo caso la existencia de un problema de fertilidad y que se restrinjan al mínimo los supuestos en los que se permita.

\section{B) Supuestos en los que se permite}

La determinación de la naturaleza de la Gxs plantea la cuestión previa o simultánea de determinar en qué supuestos se admite. Varios son los aspectos a los que se refiere la cuestión de la determinación de su ámbito.

146

1) Por una parte, debe establecerse si se restringe a aquellos supuestos en los que exista una imposibilidad patológica para gestar al niño o si, por el contrario, se abre a otros supuestos. Si se opta por la primera posibilidad, quedarían fuera las parejas homosexuales de hombres o los hombres que pretenden tener hijos en solitario, cuando, en realidad, son los "usuarios

\footnotetext{
${ }^{26}$ Vela Sánchez, A. J. "Propuesta de regulación del convenio de gestación por sustitución o de maternidad subrogada
} en España", en La Ley, 3 de mayo de 2011. 
naturales" de la gestación por sustitución. El supuesto resuelto por la Resolución de la DGRN y por las famosas sentencias de Valencia no entrarían en su ámbito de aplicación.

2) Por otro lado, es necesario que la ley determine si se exige o no que exista aportación genética de, al menos, uno de los padres de intención, sea hombre o mujer, es decir, que exista alguna vinculación genética con el niño, o si es posible que exista una aportación genética totalmente ajena a los padres de intención.

3) En tercer lugar, debe determinarse si se debe limitar a la gestación sin aportación genética de la mujer gestante, que sólo aporta su útero, o si, por el contrario, se permite también que la mujer gestante aporte el óvulo para la procreación. Si la primera solución es retenida, la GXs pasaría siempre por una fecundación in vitro con implantación del pre-embrión en la mujer gestante. Quizá esta solución sea la más apropiada porque, además, acentúa la "desvinculación" de la mujer gestante respecto del niño.

Combinando todas estas posibilidades, el legislador podrá optar por un modelo restrictivo o por uno permisivo.

En el modelo restrictivo, la gxs se contempla exclusivamente como una técnica más de reproducción asistida en la que se exige siempre la imposibilidad patológica de una mujer para gestar y la existencia de un vínculo genético con, al menos, uno de los padres de intención. Es el modelo que propone Vela Sánchez.

El que podríamos llamar modelo abierto o permisivo, pasaría por no exigir la imposibilidad patológica de la gestación ni la necesidad de aportación genética de los padres de intención.

Es en la determinación de los supuestos de admisibilidad donde se centrarán las dificultades mayores de una hipotética regulación. Si el legislador adopta una posición restrictiva, todos aquellos que no encajen en su campo de aplicación, que serán la mayoría, seguirán recurriendo a la realización de esta práctica en el extranjero, reproduciéndose los mismos problemas que hoy día existen para el reconocimiento o la determinación de la filiación de los niños así nacidos. Pero si el legislador opta por una solución en la que se permita recurrir a la gxs en cualquier circunstancia, por el mero concurso del "deseo de ser padre”, entramos en un terreno peligroso en el que las objeciones éticas se acentúan y que, como advierte $\mathrm{H}_{\mathrm{AUSER},}{ }^{27}$ nos conduce a crear una teocracia del hombre sobre la naturaleza en materia de reproducción.

\footnotetext{
27 HAUSER, J. "La gestation...", op. cit., p. 94.
} 
MONTSERRAT PEREÑA VICENTE

\section{c) El consentimiento como determinante de la filiación}

La cuestión de los consentimientos exige determinar quiénes intervienen en la convención de gestación con carácter de parte, y por tanto han de consentir, quiénes han de asentir y respecto de quiénes se va a determinar la filiación.

Si se aproxima la GXs a la adopción, no es posible pensar que este procedimiento se efectúe únicamente en las clínicas de reproducción asistida, sino que la intervención de la administración pública se impone desde la fase previa a la concepción.

La ley debe determinar el momento en el que se presta el consentimiento irrevocable de todos ellos. Especialmente delicada es la cuestión de la prestación del consentimiento de la mujer gestante. ¿Se tendría que respetar el plazo de 30 días tras el parto que impone la ley para que la mujer consienta en que no se establezca el vínculo de filiación con el niño y por tanto éste pueda ser adoptado? Es evidente que no nos encontramos en el mismo supuesto, y aunque se aproxime la GXs a la adopción, eso no significa la aplicación en bloque de toda la normativa relativa a ésta. Entendemos que, en este supuesto, el consentimiento ha de prestarse antes, no sólo antes del parto sino antes de la fecundación, y constituye un consentimiento irrevocable, tanto por parte de los padres de intención como por parte de la mujer gestante. Consentimiento que habrá de prestarse con las mayores garantías de autenticidad y de libre formación de la voluntad.

En este caso, podríamos decir que la filiación va a quedar establecida desde el momento en que se presta el consentimiento, que es el objeto principal de la convención de gestación, aunque no su contenido exclusivo.

\section{Conclusión}

Cada vez son más los autores que abogan por la necesidad de que el legislador modifique el artículo 10 de la LTRHA para suprimir la prohibición en él contenida

148 y regular la gestación por sustitución para evitar todos los efectos perversos que la "falsa" regulación de la Instrucción de la DGRN genera.

La historia nos demuestra que ningún avance se ha logrado sin oposición, e incluso, a veces, sin una revolución, por lo que es normal que no exista unanimidad ante una propuesta de regulación de una cuestión tan sensible como ésta, en la cual, lo que para unos sería un avance para otros es más bien un retroceso, por lo que las posiciones no son fácilmente conciliables.

En segundo lugar, no es fácil encontrar un apoyo firme en ningún derecho fundamental que justifique la necesidad de regular la gestación por sustitución. 
Si el interés superior del menor aducido por la DGRN puede servir de criterio para solucionar problemas concretos, en ningún caso puede ser la base para sustentar una regulación que admita este procedimiento en nuestra legislación, ya que, a diferencia de lo que ocurre en la adopción, en la que el niño ya existe, en este caso no hay niño hasta que se concluye todo el proceso, por lo que habría que buscar otro interés o derecho en juego.

El derecho de procrear de toda persona, sola o en compañía, estableciendo un vínculo de filiación natural, incluso cuando exista una ausencia total de base natural, no es un derecho fundamental consagrado en nuestro ordenamiento jurídico ni en ningún tratado o convención internacional, aunque nuestra legislación en materia de filiación parezca dar a entender otra cosa.

A pesar de todo ello, quizá sea conveniente regular la Gxs y se encuentre un consenso, aunque sea de mínimos, para ello, para, como señala SÁnchez ArISTI, ${ }^{28}$ terminar con esa "especie de limbo extrajurídico" que genera la prohibición actual. Pero no debemos engañarnos; regular la GXs no va a solucionar todos los problemas que existen ni va a impedir que se generen otros nuevos. ¿Qué ocurrirá con los niños que ya han nacido en el extranjero utilizando esta técnica de padres de intención españoles?, ¿se va a conceder una especie de "amnistía de determinación de la filiación” con efectos retroactivos? 0, por el contrario, ¿quedarán para siempre en ese limbo por haber nacido antes de tiempo? Además, salvo que la ley no pusiera condiciones ni requisitos de ningún tipo, es decir, que permitiese recurrir a la GXs en todo caso y a cualquier persona, cosa que no ocurre en ninguna legislación de las que admiten la práctica, siempre habrá nuevos casos en los que una persona, sola o en pareja, aportando o no su material genético, recurra a una gestación por sustitución en España o en el extranjero, sin cumplir las exigencias de la ley, y entonces, como ahora, se tendrá que valorar, caso por caso, si una vez nacido ese "hijo fuera de la ley" existe un interés superior del niño que permite determinar la filiación o reconocer la que se ha determinado en el extranjero, sin ajustarse a la legalidad vigente en España.

${ }^{28}$ SÁnchez Aristi, R. "La gestación...", op. cit., p. 37. 